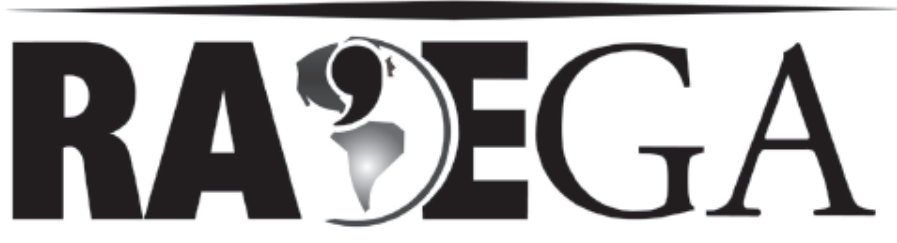

O ESPAÇO GEOGRÁFICO EM ANÁLISE

\title{
REPRESENTAÇÕES INDÍGENAS: TERRITORIALIDADES E IDENTIDADE - UMA APROXIMAÇÃO TEÓRICA
}

\author{
INDIGENOUS REPRESENTATIONS: TERRITORIALITIES \\ AND IDENTITY - A THEORETICAL APPROACH
}

\author{
Adnilson de ALMEIDA SILVA ${ }^{1}$
}

\section{RESUMO}

O presente artigo reflete algumas preocupações sobre as representações indígenas e busca, com isso compreender a visão de mundo, através das territorialidades e identidade. Desse modo, a nossa compreensão se baseia em experiências e vivências em campo com aplicabilidade da pesquisa participante com o Coletivo Kawahib da Terra Indígena Uru-Eu-Wau-Wau, no Estado de Rondônia, e na análise de referenciais teóricos que sustentaram as reflexões e preocupações para elaboração do trabalho. $\mathrm{O}$ artigo apresenta em si um como resultado as reflexões e preocupações necessárias para o desenvolvimento de um conceitual teórico que denominamos de "marcadores territoriais", com ênfase no exercício das experiências e vivências do espaço de ação dos indígenas e que podem ser estendidas no campo geográfico e demais áreas de conhecimento correlatas.

Palavras-chave: Identidade; Indígenas; Representações; Territorialidades.

\footnotetext{
1 Mestre em Geografia pela Universidade Federal de Rondônia - UNIR. Doutor em Geografia pela Universidade Federal do Paraná - UFPR. Professor do Departamento e do Programa de Pós-Graduação Mestrado em Geografia - UNIR. Pesquisador do Grupo de Estudos e Pesquisas sobre Modos de Vida e Populações Amazônicas - GEPCULTURA. E-mail: adnilsonn@gmail.com
} 


\section{ABSTRACT}

This article discusses some concerns about the indigenous representations and search with this understanding the worldview through territorialities and identity. This way, our understanding is based on experiences in the field with applicability of research participant with the collective Kawahib of the Terra Indígena Uru-Eu-Wau-Wau in Rondônia, and theoretical analysis benchmarks that argued the reflections and concerns for the preparation of the work. The article presents itself as a result the reflections and concerns necessary for the development of a theoretical concept called "territorial markers", with emphasis on exercise of experiences and the experiences of indigenous and action of space that can be extended in the geographical field and other related areas of knowledge.

Keywords: Identity; Indigenous; Representations; Territorialities.

\section{CONSIDERAÇÕES INICIAIS}

Entendemos como de fundamental importância, a Geografia abordar, discutir e procurar compreender a complexidade dos mais distintos modos de vida das populações humanas, de maneira que possibilite a compreensão das identidades e suas territorialidades, visto que nelas se inserem questões sociais, econômicas, ambientais e culturais, nas quais essas populações constroem sua visão de mundo.

As representações das populações indígenas apresentam em suas cosmogonias e simbologias, elementos indispensáveis às análises e abordagens da Geografia Cultural, visto que delas emanam o entendimento acerca das identidades e territorialidades.

Em análise das diferentes culturas humanas, observamos que a representação é imprescindível ao processo da identidade indígena, em suas relações de construção, defesa territorial, memorial cosmogônico, porque resulta da interpretação do seu microcosmo por meio das relações cosmogônicas, que oferecem sentido à vida e à própria existência.

Desse modo, a base conceitual parte dos princípios e enunciados das representações, cuja aproximação auxilia a compreensão dos modos de vida e possibilita construir um caminho teórico para a discussão da territorialidade e identidade indígenas. Todavia, não se trata de algo pronto e acabado, mesmo 
porque em cada cultura humana as representações também são percebidas, sentidas e vivenciadas distintamente em decorrência das relações e atributos de construção e de visão de mundo, ou seja, o compartilhamento de seu microcosmo.

\section{O SIMBOLÓGICO COMO COMPREENSÃO DO GEOGRÁFICO: UMA ANÁLISE CASSIRERIANA}

Em "Ensaio sobre o Homem", Cassirer (1994, p. 96-141 [1944]) defende que a compreensão decorrente do conhecimento humano é verificada como processo, cuja ocorrência se dá a partir de três modos que evoluem gradativamente, cuja síntese é o próprio conhecimento: o concreto (ideal), o perceptual (sensorial) e o simbólico - sendo esse último o amálgama dos dois anteriores e, dessa maneira atua como intercessor entre espírito e matéria.

Ao abordar o modo concreto ou expressivo, esse autor entende que não existe dissociação entre o que pode ser visto, escutado e atingido, isso porque nele se presentificam as emoções que, em seus atributos, valorizam as coisas pela aparência e estabelecem diretamente as relações espaço-tempo.

No modo perceptual é o lócus em que as coisas se estabelecem com qualidade e permitem ordenar o espaço-tempo, e nele se realiza as particularidades do significado, isto é, o percebido envolve o interpretado a partir de signos detectados e gerados pelos sentidos, o que de fato, constitui-se como informação elevada que soma a outros dados sensoriais específicos e serve de orientação no interior do ambiente percebido, sendo essa para a representação e presentificação de mundo, no qual os "marcadores territoriais" são componentes intrínsecos dos coletivos ${ }^{2}$ humanos.

Por seu turno, o modo simbólico se define como o ambiente conhecido ou experimentado indiretamente pela análise interpretativa das representações simbólicas. Entretanto, não possuem, necessariamente, vínculo obrigatório com a experiência vivida. Em seu contexto maior, o modo simbólico guarda a

\footnotetext{
${ }^{2}$ Conceito definido por Latour (2004, p. 373) como "um procedimento para coligar as associações de humanos e não-humanos", interligado ao conceito de "definição performativa de grupo" porque é "algo ininterruptamente constituído" (LATOUR, 2005, p. 34,35).
} 
familiarização - apresentação - com o conhecimento abstrato - representação (CASSIRER, 1992, p. 239 [1925]; 1968, p.42-116 [1944]).

De modo sintetizado, esses três modos progressivos podem ser representados em níveis distintos qualitativamente, mas que se encontram interligados, em que pode ser constatado que tais diferenças refletem novos olhares em relação à vivência e às experiências anteriores e presentes, sendo que os "marcadores territoriais" se concretizam a partir dessa interligação.

Logo, esse processo considera o transformar e aditar das experiências como formato simbólico, em que, por meio dos símbolos, a informação sensorial é manifestada em sentido, e sua atribuição acontece como uma metodologia de análise de espaço, tempo e causalidade, e caracteriza-se como forma simbólica, sendo

[...] a energia do espírito em cuja virtude um conteúdo espiritual de significado é vinculado a um signo sensível concreto e lhe é atribuído interiormente [...] a linguagem, o mundo mítico-religioso e a arte se nos apresentam como outras tantas formas simbólicas particulares [...] (CASSIRER, 1975, p. 163 [1956]).

A proposição da explicação para a informação dos sentidos ou sensorial apoia-se na influência do contexto cultural - no caso dos indígenas, na cosmogonia - em que nenhum grau de conhecimento ou de experiência sucumbe-se após sua apreensão, semelhante aos conceitos anteriormente integrados, com isso atinge novos atributos de representações. Aqui, entendido como aquisição de cultura e de espacialidade distintas da sua.

A nova atribuição permite expandir a cultura em geral e da ciência em particular como processo contínuo de construção de tempos no espaço (ideia) e de vivências do espaço concreto (vida) para o espaço perceptivo e abstrato, o que irá se constituir em representações e ressignificações de mundo. Esses elementos, por sua ocasião, qualificam o espaço de forma heterogênea como um fenômeno fundamental da vivência de qualquer coletivo humano e não se limita apenas às sociedades tradicionais ${ }^{3}$ (CASSIRER, 1968, p. 194 [1944]).

\footnotetext{
${ }^{3} \mathrm{O}$ termo tradicional referenciado é aplicado aos demais coletivos, cujo modo de vida ou experiência socioespacial é marcado pela lógica de relações estreitas com o meio, ou seja, uma visão e interpretação do mundo, cujos valores de formas, representação simbólica e presentificação e são distintos da sociedade envolvente, porque é fundamentada na sobrevivência material e espiritual na territorialidade, e, desvinculada da ideia de apropriação dos recursos com finalidade econômica. Assim, é detentor de qualidade conceitual próxima àquela desenvolvida com os indígenas.
} 
Essa assertiva possibilita o encontro de relação entre o Eu e o Tu, entre Eu e o Outro Eu, em que o Outro deixa de ser tipo, objeto e torna-se conhecido com nome e história cessando o estranhamento. Nessa conjunção, já não se discute mais o homem lúdico ou animal rationale, e sim o animal symbolicum (CASSIRER, 1968, p. 71[1944]) com seus atributos em realizar-se e representar-se perante o mundo por meio de seu espaço de ação.

É preciso elucidar que o animal rationale ou animal symbolicum, na verdade é o ser humano ou o próprio indivíduo. No caso dos indígenas, a explicação sobre o indivíduo não é completa, isso porque essas populações entendem o humano como o $E u$, o Outro $E u$ - a multidão que existe dentro de cada ser e não-ser - cuja pertença ocorre com a "fabricação de corpos" 4 e dá o sentido da pluralidade ou o Nós, ou seja, a configuração do divíduo, cujo conceito é caracterizado por Strathern (2006, p. 40-41): "as pessoas são frequentemente construídas como o lócus plural e compósito das relações que a produzem".

Do modo como entendemos, assim como os indígenas compartilham o seu microcosmo ${ }^{5}$, todos os seres e não-seres são partes integrantes de um mesmo conjunto, em que todos experimentam e vivenciam o outro por meio de valores, símbolos e representações, sendo que a territorialidade e a identidade estão intrinsicamente interligadas.

Para Cassirer, assim como para Langer (1967, p. 8; 2004 [1942]; 2006 [1953]), o ser humano em sua trajetória histórica é um ser que está constantemente experimentando os símbolos, dos quais utilizam em sua forma material. O mesmo ocorre com o pensamento simbólico, enraizado, na natureza humana como elemento principal nas ações de vida e conhecimento. Podemos afirmar, nessa inferência que o símbolo e a forma simbólica possuem uma ritualística lógica comum, cujo atributo é dar sentido à vida e às múltiplas relações com o espaço.

\footnotetext{
${ }^{4}$ Segundo Viveiros de Castro (1987, p. 31) a "fabricação de corpos" refere-se ao "conjunto sistemático de intervenções sobre as substâncias que comunicam o corpo e o mundo: fluidos corporais, alimentos, eméticos, tabaco, óleos e tinturas vegetais", nele são incluídos os seres e não-seres, porque diz respeito à espiritualidade e à holística de apreensão e visão do microcosmo.

${ }^{5}$ Conceito desenvolvido por Leenhardt (1937; 1995; 1997, p. 72 [1947]), cujo arcabouço teórico transporta a ideia de totalidade dentro de um espaço ou território conhecido por um coletivo.
} 
Sobre as formas simbólicas, a contribuição cassireriana ocorre com o discurso sobre o ser humano e está ancorada em três assertivas: a Sprache (linguagem), o Mythos (mito) e o Erkenntnis (conhecimento), que formam o símbolo, como campo de mediação entre o espírito e a essência, porque esse é imprescindível e lança-se sobre todas as disciplinas como forma a priori do espírito humano e se presentifica em tudo aquilo que é construído por meio de suas experiências no espaço de ação. Destarte, a intensidade é produzida emocionalmente pelas formas e representações inerentes ao símbolo do qual esse ser utiliza na sua compreensão e construção de mundo.

A linguagem se expressa num sistema de símbolos que atua como intercessão comunicativa entre os homens, e sua relevância permite ao homem um papel ativo e não somente um mero receptáculo dos fenômenos físicos da natureza, em vista de se colocar, se representar e se presentificar no mundo e ao mundo do pensamento.

A linguagem simbólica cassireriana autoriza ainda uma relação comparável com o inatingível, ou seja, com o não-ser, caracterizando-se como "as coisas do mundo, que existem no mundo como aparente, como fenômeno, como elas se apresentam" (CASSIRER, 1994, p. 81-96 [1944]). Esse fato se dá em virtude que o ser humano insere-se no meio, é integrante do meio, é o próprio meio, em suas relações, é a multidão e a síntese do todo que compõe seu microcosmo.

\section{ALÉM DOS SÍMBOLOS É POSSÍVEL ENTENDER A TERRITORIALIDADE E IDENTIDADE INDÍGENAS?}

Essa percepção existente em Cassirer remete ao conceito de cultura e sua edificação é decorrente das experiências socioespaciais por meio do simbólico e mostra-se como síntese metodológica. No nosso caso, a compreensão se ajusta a essa síntese e abrange ainda três princípios fundamentais: as formas simbólicas, a construção da territorialidade, as interrelações entre os coletivos humanos. 
O primeiro contextualiza as representações como dialeticamente responsável pela constituição do conhecimento humano e opera como ambiente explicativo geográfico por meio da inter-relação da materialidade dos objetos e a imaterialidade construída pela cosmogonia e assentada nas concepções de espaço de ação (CASSIRER, 1968, p. $40-50$ [1944]) e formas simbólicas (CASSIRER, 1953-1957, p. 20-249 [1929]).

Nesse aspecto, os "marcadores territoriais" são formas simbólicas que auxiliam na compreensão da cultura e das múltiplas relações que são portadoras de construção cosmogônica e do modo de vida de determinado coletivo humano, visto que refletem formas

[...] diversas, antagónicas ou complementares, que participam na escolha dos espaços e na construção das formas sociais impostas [...] implicando o conhecimento, as concepções e as utilizações sociais dos territórios [...] das técnicas adotadas para levar a cabo a estruturação das formas e das práticas sociais: territórios, identidades, concepções e práticas [...] (HENRIQUES, 2003, p. 03).

O segundo princípio mantém estreita ligação com o primeiro e apresenta a territorialidade como resultante do espaço de ação e experiências socioespaciais como realidade material e imaterial construída simbolicamente pelos coletivos. É com a territorialidade que também é explicada pela cosmogonia, na qual a edificação de demiurgos explica a ordem dos seres e não-seres colocados no microcosmo, constitui-se como ordenamento do espaço identitário, que permite a distinção de coletivos e de culturas.

Nesse caso, entre os indígenas existem culturas muitas vezes semelhantes, mas não idênticas, em razão da concepção adquirida pela cosmogonia, assim como os significados, representações, territorialidades também se presentificam com quesitos distintos de apreensão e visão de mundo.

O último princípio é construído com o desenvolvimento das interrelações entre os coletivos humanos e os não-seres, e relaciona-se com os anteriores. O estabelecimento das relações realizadas entre os coletivos distintos possibilita a gênese de marcas - identidade e cultura - no espaço e contribui profundamente no pertencimento, como para modificações do modo 
de vida e cultura de determinada coletividade, ou como afirma Sahlins (1997, 1997a, 2003 [1985]) em "mudança e permanência".

Esses três princípios, como elementos das formas e representações simbólicas, não podem ser caracterizados solitariamente, visto que ocorrem dinamicamente e sua compreensão está sustentada em múltiplas relações, sejam cosmogônicas, sociais, ambientais, entre outras.

Por meio da forma simbólica, a cosmogonia, a materialidade, a cultura, os valores e os mitos contribuem para a construção e organização do espaço de um coletivo indígena e seguem uma matriz estruturante de rito singular, revestidas de valores espirituais, cuja característica maior é distinguir-se na forma de representar em relação aos demais coletivos humanos.

Sob esse aspecto, uma ação decisiva dos divíduos relativos "à sua vida e ao seu mundo, pode-se fundar nos usos propositados de intuição decisiva da organização social” (VIVEIROS DE CASTRO, 2006, p. 403-447 [2002]), e sugere que a cada atualização da vida prática do coletivo, dinamicamente a cultura se refaz como forma de se representar e presentificar, contudo a ideia central cosmogônica cristaliza-se como "permanência" 6 .

As culturas são conduzidas pelas representações e simbologias, nas quais a historicidade, a espacialidade e territorialidade são construídas através dos valores considerados mais importantes de um coletivo. Os inúmeros símbolos são salvaguardados em sua estrutura simbólica e expõem-se como históricos e simbólicos em suas formas, isto é, significativas e continuamente verificadas nas mais diversas paisagens humanas, de onde se alude, como "a forma simbólica que fornece a função característica a cada objeto ou a uma ação, considerando-se ainda os valores próprios e imediatos ou históricos" (ALMEIDA SILVA, 2010, p. 67).

Desse caráter, as diversas interpretações conceituais acerca do signo e símbolo vinculam-se a diferentes visões, fenômenos, métodos e relação de temporalidade, visto que "o homem cria símbolos como signos arbitrários em relação ao objeto" (GUSDORF, 1960, p. 7).

\footnotetext{
${ }^{6}$ Essa permanência está vinculada diretamente aos mitos e à ideia fundante e estruturante no interior da cosmogonia, na qual podemos situar a visão de criação e ordenamento do microcosmo de determinado coletivo. É a permanência que dá sentido à identidade e à territorialidade do coletivo em suas formas de representação simbólica.
} 
O símbolo expressa as multirrelações dos divíduos em sua busca de compreender as formas, suas heterogeneidades, expressões, interpretações simbólicas individuais e coletivas realizadas no interior das coletividades.

[...] O símbolo diferencia-se essencialmente do signo por ser, este último, uma convenção arbitrária que deixa alheios um ao outro 0 significante e o significado (objeto ou sujeito), ao passo que o símbolo pressupõe homogeneidade do significante e do significado no sentido de um dinamismo organizador [...] (CHEVALIER; GHEERBRANT, 1998, XVI).

O simbólico se constitui em sua vasta função explicativa ou como construtora de um sistema de relações complexas e possui um caráter complementar, uma conexão entre o mundo físico e o ideal.

É em sua recorrência que a inquietude humana encontra o abrigo indispensável como forma de se representar e presentificar simbólica e socialmente nas culturas. Culturas estas que são produzidas por meio das heranças cosmogônicas e culturais que são capazes de explicar o existir do e no microcosmo, pelas mais variadas razões, entre elas: os medos e inseguranças do desconhecido, sortilégios, espiritualidades, esperanças e sonhos.

Esses eventos de representação simbólica, sempre ou quase sempre, resultam da constatação empírica que o ser humano observava materialmente na natureza ou sensorialmente os aspectos invisíveis que proporcionam à constituição mental do divíduo ou das coletividades, nas quais os símbolos justificam a existência de objetos e não objetos, de seres e não-seres.

\begin{abstract}
Nessa compreensão, os símbolos utilizados pelo divíduo para a representação de suas representações e presentificações no mundo objetivo são detentores de autonomia especial, neles estão contidos a ideia de espaço como esfera ou metáfora simbólica de representação do lugar e servem de mediação entre o divíduo e os seres e nãoseres. Desse modo, o espaço surge em primeiro lugar, como configuração e objeto da percepção imediata da realidade, ou seja, trata-se de um mundo fenomênico, e que passa a ser e ter sentido quando provido de valor simbólico (ALMEIDA SILVA, 2010, p.68-69).
\end{abstract}

Nessa ótica, somente o símbolo é dotado de qualidades e capacidades de representação dos fenômenos, não só através dos vocábulos, mas, sobretudo, pela propriedade das ideias, valores, inclusive relacionado aos não- 
seres "porque a linguagem simbólica está indissociadamente unida à imaginação" (CASSIRER, 1968, p. 186-189 [1944]).

A linguagem como expressão no simbólico é uma relação natural, uma ponte entre o ser e o não-ser, na qual se revela e consolida a relação de identidade como manifestação destes. Essa interposição é fundamental na apreensão estruturante das ações e experiências humanas - mito, religião, linguagem, história, matemática, física, direito e arte - e permite-nos analisá-las e compreendê-las como um todo orgânico com múltiplas lateralidades propiciadas pelo espaço de ação e experiências socioespaciais.

No caso dos Jupaú, a linguagem e o referencial de memória caminham juntas, como descreve o depoimento do indigenista Francisco Flávio dos Santos Ribeiro - "Chicão", em maio de 2006, sobre o restabelecimento da antiga maloca-cemitério, denominada Iñamõrarikãgã:

[...] A primeira vez que os Jupaú voltaram à Iñamõrarikãgã, ocorreu aproximadamente há quatro anos, todos se abraçaram, choraram copiosamente e cantavam relembrando os parentes mortos. Os espíritos de seus antepassados vivem no presente de cada um e na casa de cada um, como uma proteção à família contra os inimigos e as coisas ruins deixadas por Anhangá (espírito mau) [...] (ALMEIDA SILVA, 2010, p. 208).

Destarte, a linguagem é parte integrante da construção da territorialidade e dos "marcadores territoriais" indígenas, cujas estruturas ocorrem pela cosmogonia, se inserem no espaço de ação relacionando diretamente os seres e não-seres dos rios, floresta, terra e da vida em coletivo, culminando com o Are (Nós) como Coletivo e o Ore (Nós) no qual se insere aqueles que não estão diretamente vinculado aos Jupaú (ALMEIDA SILVA, 2010, p. 227).

Esse espaço de ação abordado por Cassirer é repleto de formas, símbolos e sinais que se situam em categorias distintas, contudo se complementam de formas simbólicas. Assim, o símbolo encontra-se devidamente conectado ao mundo de significados, porém o sinal é possuidor das artificialidades e convencionalidades e integra o mundo material do ser.

Os inúmeros exemplos registrados na história da humanidade justificam essa argumentação quando ponderamos sobre os diferentes tempos dos coletivos humanos, que "aprisionados" à ideia de espiritualidade como forma, representação simbólica e presentificação do mundo, comporta em sua 
vivência os aspectos cosmogônicos, valores morais e ritualidade. Esse contexto permite o estabelecer de relações e assenta o divíduo frente à relação intrínseca com a espiritualidade e aproxima-o de sua transcendentalidade através da realização de deveres, oferendas, rituais, sacrifícios e veneração, como condição de troca simbólica.

Essa relação, além de transportar ao caráter da identidade, ajuda-nos a compreender a territorialidade, porque as mais diversas e diferentes coletividades, ao longo de seu processo cosmogônico e histórico, encontramse sob a égide das representações, formas simbólicas e presentificações, sendo que essas acarretam a organização de sua relação material e atingem a transcendência.

É nesse momento que a existência dos mitos e ritos, presentificados e representados por suas simbologias cosmogônicas, oferece vazão ao entendimento da territorialidade e da identidade, como "marcadores territoriais" de um coletivo.

No caso dos ritos, percebemos que as inúmeras práticas e experiências vivenciadas nas coletividades propiciam à reflexão de suas trajetórias humanas, em que os "sofrimentos" e os "beneplácitos" da vida conectam-se ao cumprimento de códigos cosmogônicos e, assim, às ações humanas se realizam e apoiam na vontade e na mediação espiritual, inclusive no que se refere ao enfrentamento com o desconhecido.

É preciso situar que os "sofrimentos" e "beneplácitos" se inserem nos mitos e transportam as experiências dos divíduos e das coletividades, como uma das formas de organizar o microcosmo.

A regulação das atividades humanas dos coletivos, como caçar, pescar, plantar, colher, casar, ter filhos, morrer, sepultar os mortos, realizar lutas, conquistar territórios, entre outras ações é resultante desse processo conectivo mediador e transcendente do espiritual com o material, e exige do coletivo o cumprimento de inúmeros ritos e rituais herdados, cosmogonicamente, pelos mitos propostos pelos demiurgos que criaram o mundo e seus objetos - que também são seres portadores de espiritualidade e de territorialidade. 
Constitui-se nos rituais de passagens e outros rituais a realização corporal, espiritual, identitária e territorial dos coletivos, porque neles - rituais e ritos - contêm o ideal cosmogônico repleto de linguagem, códigos, valores simbólicos, representações e presentificações simbólicas que sustentam a existência e a apreensão dos seres e não-seres. Os rituais de passagem da menina para a fase adulta e do Yreruá ${ }^{7}$ dos Kawahib Jupaú consubstancia esta afirmação, porque se revestem de fenômenos tanto materiais quanto espirituais.

Dessa relação entre o material e o imaterial decorre a construção cosmogônica dos "marcadores territoriais" como compreensão das formas e representações simbólicas e presentificações mediadoras do modo de vida. No caso dos indígenas é evidente pelas experiências no espaço de ação que o microcosmo é holístico e transcende à materialidade - tudo se conecta - e a supressão de qualquer fenômeno componente da cosmogonia resulta em desequilíbrio que alcança surpreendentemente a todos, seja seres ou nãoseres.

Essa habilidade humana de perceber os sentidos e os significados possibilitou a promoção de mudanças através da concepção e organização da cultura religiosa, social e intelectual presentes nas representações de mundo, como elemento de conexão transcendental entre a matéria e o espírito. Os estabelecimentos de rituais, de doutrinamento com valores éticos e morais completam o arcabouço necessário, no caso dos coletivos para explicar a própria existência do microcosmo.

Em nosso diálogo, na tentativa de desenvolver uma teorização, compreendemos que a territorialidade indígena é um componente acessível e aberto, devido a sua expressão de transcendência, como resultado das experiências socioespaciais permeadas de formas materiais e imateriais, incorporando ainda à representação espacial com signos, códigos, símbolos, espaços de representação constituídos pelo concreto e o imaginário. Aqui se manifestam o tempo e o espaço como essenciais à apreensão do divíduo em

\footnotetext{
${ }^{7}$ É um ritual de celebração da vida sobre a morte, da vitória sobre os inimigos. Nele a manifestação ocorre por meio de danças, orações e músicas Kawahib, são tocadas em dois tipos de flautas de bambu ou taquara, a maior chamada de Yreruá e a menor de nhumbiá que marcam sons distintos.
} 
representar o mundo ou de concebê-lo intuitivo e empiricamente sua visão, com isso se qualifica o espaço como relacional.

Entendemos não ser possível realizar a análise da territorialidade e da identidade indígenas através da exclusão dos símbolos, representações e presentificações simbólicas, porque os divíduos e as coletividades possuem a compreensão que o todo está interligado de forma intrínseca.

\section{A COSMOGONIA COMO ELEMENTO FUNDANTE DAS IDENTIDADES E TERRITORIALIDADES}

[...] Nunca somos um só, somos sempre uma pequena multidão que vive dentro da gente buscando formas de compreender nossa passagem por este mundo. Esta multidão age em diferentes direções e nos dão diferentes razões para viver (Daniel Munduruku).

É imprescindível destacarmos que os símbolos e representações encontram-se coadunados com a memória dos coletivos indígenas, que por sua vez alicerçam-se na relação com a ancestralidade cosmogônica e territorial. Sendo que os "marcadores territoriais" são representações e presentificações que acessam o desenvolvimento das atividades cotidianas e exercem o papel no fortalecimento cosmogônico por meio da espiritualidade, como exemplo as malocas antigas - mas não somente elas (ALMEIDA SILVA, 2010).

Essas malocas são "marcadores territoriais" ou referenciais de territorialidade e constituem-se nos centros referenciais de cerimoniais, em que se concretizam os rituais sociais e espirituais e despertam os sentimentos originários de reverências, medo, orgulho e alegria, ampliados e multiplicados como fenômenos imprescindíveis à identidade e ao pertencimento cultural.

No caso de vários indígenas na Amazônia, essas malocas-referenciais de espiritualidade e territorialidade, que possibilitam o reencontro simbólico não exclusivamente com as formas e presentificações nos túmulos de parentes falecidos antepassados, exprimem também o processo de permanência da organização sociocosmogônico e territorial. Nelas se celebram a vida, a oportunidade de transcendência espiritual, o congraçamento social, a 
manifestação dos ritos e rituais, a arte e o agradecimento pela trajetória percorrida por meio da espiritualidade.

Para a compreensão da cosmogonia indígena é necessário mergulhar na vivência e na experiência do espaço de ação de determinado coletivo, uma vez que o entendimento perpassa uma visão imediata e simplista e remete evidentemente ao jogo das relações fundante e estruturante de construção cosmogônica, cujo sentido só é percebido e sentido através das experiências e modos de vida acumuladas ancestralmente.

As populações indígenas, normalmente, têm como base a percepção da profunda interdependência entre o mundo da natureza (vegetais, animais, rochas, cursos d'água, entre outros) e o mundo dos humanos, entendendo a natureza como algo vivente com quem pode interagir e estabelecer uma comunicação constante, apoiada numa visão cosmológica integradora (AGUILERA URQUIZA, 2006, p. 03).

A visão cosmogônica é um processo sociocultural, do qual as representações sociais e simbólicas atuam e são instrumentos que permitem a defesa da integridade física, da identidade cultural e da territorialidade, efetivadas pela ancestralidade imemorial. Razão essa que é o próprio constructo de mundo, aqui entendido como microcosmo que em sua representação é a própria existência e a existência das relações e correlações de atributos, os quais justificam a presença do ser e no ser inserido no mundo.

Entendemos que essa relação é um dos atributos fundantes da territorialidade e como tal se reveste de identidade, cujo princípio possui características peculiares de cada cultura, contendo nela não somente os aspectos de materialidade, mas também o sentimento e as representações simbólicas. Como categoria de análise, permite-nos compreender suas múltiplas dimensões, seja em momentos de tranquilidade ou de conflitos, pois transportam consigo um conjunto de valores significados decorrentes da construção cosmológica de cada coletivo humano.

Nessa consideração, a identidade cultural não está alheia à territorialidade, antes de tudo é um componente intrínseco dessa relação e realização, conforme assevera Montibeller-Filho (2004, p.34) que "somente 
pode-se entender a natureza observando suas relações concretas com a sociedade ao longo da História [...] no contexto das estruturas que a sociedade cria para possibilitar sua própria existência [...]".

No caso em questão, essa natureza para o indígena é o seu próprio microcosmo, isto é, ele está presente na natureza, é integrante da natureza. Ele é a própria natureza, em decorrência do processo cosmogônico que dá sustentação e estrutura seu mundo.

Principiando-nos nessa consideração, as representações, como dialética responsável pela construção do conhecimento humano atua como elemento de explicação, em que a análise geográfica se circunscreve nas relações sociais, territoriais e de representação, por meio da inter-relação da materialidade dos objetos e a imaterialidade construída cosmogonicamente. Destarte, sua fundamentação encontra respaldo na teoria da representação e do espaço de ação, desenvolvidos por Cassirer (1968), como contexto explicativo das relações de construção do microcosmo.

Com evidência na premissa cassireriana, o conceito de "marcadores territoriais" 8 apresenta-se como um dos elos para a compreensão da cultura e suas múltiplas relações. Relações estas que permitem situar os aspectos de defesa e legitimidade do território, o seu significado, símbolos e signos, cujo elemento estruturante e fundante reportam-se diretamente às cosmogonias construídas distintamente pelos coletivos indígenas.

Os "marcadores territoriais" da maneira como compreendemos
resultam do simbólico, experiências pessoais, vivências
socioespaciais ou espaço de ação, os quais estão inseridos nos
valores das experiências objetivas, subjetivas e intersubjetivas de
(re)construção simbólica dos divíduos e coletividades na organização
estruturante do todo.
Os "marcadores" estão qualificados de nuances psicossimbólicas, em
que é possível perceber a dimensão das experiências como local
apropriado para a manifestação objetiva e subjetiva das formas,
representações simbólicas e presentificações dividuais e coletivas e
de sua permanente ressemantização e ressignificação.
Os "marcadores territoriais" referem-se não somente aos aspectos
meramente físicos ou naturais em si mesmos, mas remetem a um

\footnotetext{
${ }^{8}$ ALMEIDA SILVA (2010) desenvolve em sua tese dois grupos de "marcadores territoriais", sendo: a) estruturantes - vivos, simbólicos, fabricados, históricos, musicais, funcionais, linguísticos, cosmogônicos, perceptovisual-sensoriais, estéticocorporais - esses ocorrem a partir da vivência e experiência de um coletivo e é produzido pela relação intracoletivo no espaço de ação; b) estruturadores - são aqueles que são construídos com a influência exógena ao coletivo, mas que exercem influências na relação social de determinado coletivo humano, notadamente sobre indígenas e populações "tradicionais".
} 
conjunto de relações de relações simbólicas que ligam o divíduo aos seres e não-seres, comportando ações que possibilitam distinguir diferentes modos de vida (ALMEIDA SILVA, 2010, p. 121).

O papel dos "marcadores territoriais" como representações e presentificações simbólicas situa-se no espaço de ação, legitima o geográfico, sendo que sua inferência consubstancia como componente primordial do conhecimento imaginário como sendo originado

[...] a partir da reprodução de uma imagem visual, que substitui o real através da lembrança, provocada por fragmentos do real. $O$ objeto pode ter sido anteriormente percebido, como pode ser novo, produzido pelas capacidades criativas e a representação (KOZEL, 2004, p. 223).

Portanto, o espaço de representação é constituído por múltiplas e relações complexas que ao interagirem-se norteiam a análise geográfica de compreensão do espaço, e é fundamentada na teoria das representações. $O$ direcionamento desta teoria vincula-se aos aspectos da mnese coletiva e individual, interioridade e exterioridade, materialidade e imaterialidade, cujo resultado é presentificado nas relações de cotidianidade de determinado coletivo.

A abrangência acerca do propósito dos elementos e aspectos de construção da territorialidade, identidade e cultura, assim como as representações sociais não podem ser vistas por apenas um ângulo analítico, em decorrência das definições dos "marcadores territoriais". Isto ocorre porque esses possuem dinamicidades distintas, cuja apreensão se sustenta em múltiplas relações de análise, incluindo-se a variável tempo e espaço na atualidade.

Nesse propósito, compete à Geografia contribuir para o debate das questões indígenas, mesmo porque esse campo do conhecimento desde sua formatação epistemológica possui como objeto de estudo a relação ontológica, a cultura e a natureza.

A situação que ora se apresenta é justificada pelo papel da ciência, na qual a Geografia, na afirmação de Andrade (1987, p. 66) "tem a responsabilidade de analisar a própria sociedade, as relações que influem no 
tipo de espaço produzido e explicar a razão de ser da ação da sociedade sobre esse espaço".

\section{TERRITÓRIO E TERRITORIALIDADE INDÍGENA: UM BREVE DELINEAMENTO}

Entendemos que a territorialidade indígena não pode ser compreendida sem que se considerem os aspectos cosmogônicos de inúmeros coletivos em suas culturas e espiritualidades, como manifestação do "sagrado", que são reverenciados e ultrapassam os limites da racionalidade. Dessa maneira, principalmente as malocas são lugares de interface do mundo material com um "espaço transcendente", e que propiciam a construção referencial do território e da territorialidade.

A concepção da territorialidade para os indígenas é posterior à materialidade, visto que a gênese é obra dos demiurgos que com suas criatividades e espiritualidade realizaram obras como atributos inatingíveis aos humanos e permitiram a criação e existência destes. Assim, definiram a própria territorialidade para que os humanos encontrassem seu espaço de ação e desenvolvessem as experiências no espaço. Isto, quer dizer que os demiurgos acessaram caminhos orientadores entre seres e não-seres para que os divíduos pudessem se realizar como coletivo.

A partir desse princípio, o caráter apresentado pelos demiurgos aos humanos é que não há um território amorfo, sem a existência dos seres e nãoseres, mas que por meio das experiências e dos aprendizados esses divíduos e coletividades produzem "marcas" ou "marcadores territoriais", dotadas de qualidades inerentes à realização do território e da territorialidade.

No aspecto de construção cosmogônica, os coletivos possuem uma relação introspectiva, ritualística e reverencial, em que os valores têm sido de permanência e manutenção simbólica, ao mesmo tempo em que representa a ideia de continuum sob a ótica do espaço de ação e das representações.

Percebemos na propositura apresentada que a etnogeografia ou geografia indígena é permeada de formas e representações simbólicas da cotidianidade e da ancestralidade, cujo sentido cosmogônico se operacionaliza 
com a edificação da conexão entre divíduos e coletividades, sendo essas 0 lócus privilegiado da identidade e da territorialidade.

Como expressão desse lócus, a lógica da territorialidade não está imune às formas e representações simbólicas e presentificações, inferindo que os seres e não-seres são respaldados na cosmogonia, como processo de criação e como dádiva dos demiurgos. Nesse processo, rios, montanhas, animais, enfim tudo que é conhecido possui a designação a partir da inspiração e aprendizagem originária dos seres criadores, o que inclui o arranjo de parentesco e da própria forma de exercer a territorialidade.

Nesse processo relacional, a concepção geográfica indígena está condicionada à cosmogonia, por exemplo, os rios são nominados por uma série de atributos espiritualizados como a coloração, extensão, volume, largura e encontram-se associados por estabelecimento cosmogônico aos seres e nãoseres.

Isso dá sentido ao uso do rio e dos seres e não-seres que ali habitam para a realização das atividades que garantam a sobrevivência do coletivo, ou seja, como um código regulador da própria existência humana. Nesse caso, certas espécies de peixes podem ser consumidas durante 0 ano todo, outras em momentos específicos e outras são proibidas porque violam o código de vivência e de conduta, que é ensinado cosmogônico e ancestralmente pelos demiurgos.

Esse procedimento nominativo das paisagens geográficas se estende às montanhas, cavernas, florestas, roçados, locais de caça e outras atividades como condição de realização do contrato social, na qual os demais seres e não-seres se constituem como integrantes do sistema cosmogônico e do microcosmo. Deste modo, entendemos que essas paisagens são investidas de espiritualidade, inclusive como moradia de todos os componentes desse sistema.

A construção da territorialidade indígena e o modo de vida como experimentam o espaço, num primeiro momento para a sociedade envolvente, parece ser algo assazmente banal e infantilizada, mas essa concepção é equivocada porque é eivada de estereótipos. Entendemos que através da 
convivência com divíduos indígenas é que se apreendem os fatos simbólicos, as representações e presentificações simbólicas, cujo contexto dos fenômenos perpassa o caráter visual e atinge o sensorial, de modo que passamos a ter uma leitura mais adequada do ambiente microcósmico.

Esse caminhar conceptivo vincula-se à cosmogonia que possui sua própria intencionalidade e espiritualidade, inspiração e situação de organização social, territorial e identidade cultural em conformidade com os desejos do ente criador ou demiurgo de cada coletivo - daí decorre a distinção territorial, social e cultural entre os mais diversos coletivos em suas representações, sendo que um mesmo objeto pode ter nominações e significações também distintas.

Os objetos, assim como os seres e não-seres são mensageiros de territorialidade e espacialidade associadas à ancestralidade e da cosmogonia, sendo que a geografia é uma representação qualitativa que reafirma as experiências vivenciadas no espaço de ação e possibilitam o entendimento do fazer geográfico, como "totalidade do ser" e da "orientação cósmica" (LÓPEZ, 2006).

$\mathrm{Na}$ configuração dos coletivos em conceber o mundo e suas territorialidades, seus meios tecnológicos e etnoconhecimentos são indicadores para a compreensão de suas culturas como importantes instrumentos analíticos do mundo, como é o caso da etnomedicina. Destarte, a geografia indígena oferece condições de "análise interpretativa com a finalidade de demonstrar a realidade inacessível materialmente, mas que se encontra intrinsecamente presente no divíduo e se realiza através das experiências adquiridas cosmogonicamente" (ALMEIDA SILVA, 2010, p. 78).

Dessa constatação, entendemos que o etnoconhecimento é próprio dos divíduos - herdados cosmogonicamente e realizado pelas experiências do espaço de ação - e acessam a espacialização e a organização de seu microcosmo como representação, na qual os "marcadores territoriais" se cristalizam juntamente com as identidades em territorialidades.

$O$ argumento sobre a representação indígena na etnogeografia envolve questões históricas, visto que o vivido e experimentado ancestralmente pelos divíduos distende-se no presente, sendo uma ordem infinita, suporta tempo e 
espaço infinitos, e rege o coletivo em qualquer momento a permanecer no seu núcleo com o ideário original.

Sob essa ótica, a representação geográfica indígena explica alguns fenômenos intrínsecos e externos como condição qualitativa da formação territorial, da identidade cultural, como pertencimento do coletivo. Dessa forma, a concepção de seu universo indígena é construída pelas vivências e percepções de seu microcosmo, ancorada na ideia cosmogônica de espacialidade ofertada pelos demiurgos, sendo que "a espacialidade é anterior ao Eu como divíduo, que por escala hierárquica encontra-se situada entre Outro divíduo superior [...] de modo a marcar a territorialidade" (ALMEIDA SILVA, 2010, p. 80).

A compreensão sobre territorialidade coletiva, como vimos, é constituída por coerência complexa oriunda da cosmogonia e seus atributos como "marcadores territoriais", cuja construção é definida pelas formas e representações simbólicas na essência de cada coletivo, e perpassam a territorialidade do Estado, porque se encontra plena de valores, sentimentos, pertencimentos e de contextos históricos mais abrangentes que a lógica desenvolvida pelo Estado-Nação. Esse é o sentido do território que se coaduna ao argumento de Bonnemaison (1981, p. 261-262):

Portanto, espaço e território não podem ser dissociados: o espaço é errância, o território é enraizamento. O território tem necessidade de espaço para adquirir o peso e a extensão, sem os quais ele não pode existir; o espaço tem necessidade de território para se tornar humano.

A experiência socioespacial dos coletivos corrobora como elemento estruturante de suas identidades culturais, pertencimentos e valores que são imprescindíveis na construção e a permanência dos "marcadores territoriais", assim como das distintas representações e presentificações simbólicas inerentes a cada coletivo. Sobre a funcionalidade e relações ocorridas na territorialidade:

Its is used in everyday relationships and in complex organizations. [...] territoriality must contain a form of communication. This may involve a marker or sign such as is commonly found in a boundary. [...] A territorial boundary may be the only symbolic form that combines a 
statement about direction in space and a statement about possession or exclusion [...] (SACK, 1988, p. 05; 21) ${ }^{9}$.

Portanto, em Bonnemaison e em Sack, verificamos que a territorialidade é uma produção humana - no caso dos coletivos é uma dádiva cosmogônica. Entretanto, ambas se revestem de concepções ideológicas e como tal está aprisionada, obedecendo ao controle e a posse, possui conteúdo simbólico e atributos de estruturas compostas com signos, significações e representações, nas quais os seres humanos não estão imunes a essas presentificações.

É sobre essa visão que a contribuição dos "marcadores territoriais" pretendeu difundir as considerações sobre a concepção do espaço com suas heterogeneidades, em interpretar o "mundo", a cultura com seus valores morais e estéticos, o continuum cosmogônico, as representações, as formas e as presentificações e evidentemente o modo de vida dos coletivos.

\section{CONSIDERAÇÕES FINAIS}

As representações dos coletivos como expressões do microcosmo se distinguem em processos de apropriação e internalização desse universo conhecido. E em sua dimensão simbólica os divíduos e dos coletivos se realizam em múltiplas relações, as quais comportam a perspectiva sociocultural, a identidade e a territorialidade.

Por essa dimensão, cada divíduo transporta consigo a própria territorialidade, visto que essa é intrínseca à própria existência do divíduo, como "marcadores territoriais" simbólicos. Nessa definição, suas representações são constituídas de vivências decodificadas no microcosmo, cujo sentido cosmogônico norteia sua vida e estabelece "o conjunto de relações internas como construtora da identidade coletiva, e externas como característica de apresentar-se perante o Outro" (ALMEIDA SILVA, 2010, p. 79).

\footnotetext{
${ }^{9}$ Seu uso ocorre em relações de cotidianidade e em organizações complexas. Territorialidade se revela como uma expressão geográfica primária de poder social. [...] territorialidade possui uma forma de comunicação. De fato, envolve um marcador ou pode assinar como é achado comumente em um limite. [...] Um limite territorial pode ser a única forma simbólica que combina uma afirmação sobre direção em espaço e uma confirmação sobre posse ou exclusão. (Tradução Nossa).
} 
Os símbolos, as representações e as presentificações simbólicas instituem à acessibilidade das relações sociais entre seres e não-seres, como moldagem contratual do equilíbrio e respeito cosmogônico entre o todo existente no microcosmo, seja material ou imaterial, e coloca os divíduos e coletividades como representações de si mesmo e do Outro Eu, ou seja, da multidão existente no interior de cada um.

Essa constatação aplica-se ao contexto da territorialidade, pois os divíduos são integrantes dessa mesma territorialidade e através das experiências no espaço de ação e outras relações constroem a identidade cultural e territorial, como condição de apreensão das heranças ancestrais e como de constructo das relações entre seres e não-seres.

Podemos dizer que a construção da territorialidade e identidade indígena envolve uma lógica de complexidade material quanto imaterial, que motiva a realização do modo de vida dos coletivos e seu fundamento estruturante origina-se da vontade e a determinação cosmogônica, em que os divíduos (STRATHERN, 2006) captam os eventos dos fenômenos como linguagem/mensagem espiritualizada, a qual orienta seus destinos e dá sentido à existência da humanidade.

Essa lógica complexa de norteamento de vida e orientadora das ações no espaço de ação possibilita a compreensão da territorialidade como representação simbólica constituidora da etnogeografia indígena, que por mediação dos símbolos, signos e sinais se presentificam nos "marcadores territoriais". Com isso, pode ser apreendido o sentido da territorialidade e identidade de determinado coletivo.

Nossa discussão não se encerra neste ensaio, porque entendemos que a complexidade da etnogeografia é muito mais ampla do que supomos, até mesmo em razão da diversidade cultural dos coletivos em sua relação cosmogônica e apreensão do microcosmo, como narrou em abril de 2007 Arimã-Ga da Aldeia Djaí (Alto Jaru):

[...] Quando saiu da maloca, a mulher grávida morreu, mas a filha que ela tinha na barriga não morreu. O marido ficou sozinho, ele fez a flecha, depois pegou a menina para proteger e aí apareceu Anhangá. Anhangá deitou-se com a menina engravidando-a, depois a levou para pintar com jenipapo, lá no jenipapeiro. Aí ele fez a pintura, então 


\begin{abstract}
disse: "vamos pintar nosso filho". Jogou o jenipapo fora e depois Anhangá desapareceu. Quando foi embora, ele virou capim, depois virou abelha, depois jaguar (onça), e saí por aí fazendo suas travessuras e maldades. Gosta de assustar as crianças. Quando morre alguém, tem que chorar muito e rezar coisas de índio senão Anhangá volta para levar embora os outros parentes. Fazemos 0 Yreruá para espantar o espírito de Anhangá [...] (ALMEIDA SILVA, 2010, p. 256).
\end{abstract}

A etnogeografia, no caso dos Jupaú, é relevante pela dimensão cosmogônica de seus valores ancestrais e são evidenciados, principalmente, com os constantes retornos às antigas malocas-cemitérios - "marcadores territoriais" - plenas de representações simbólicas que permitem a compreensão dos fenômenos espirituais e da imaterialidade. Esses "marcadores" também apresentam em seu contexto, o lócus da vivência, da experiência do espaço de ação, da cultura e principalmente como referência espiritual e territorial.

Portanto, o caráter aferido na etnogeografia é a possibilidade de entendimento as populações "tradicionais" e os coletivos indígenas, nas suas múltiplas relações endógenas e exógenas em seus espaços de vivências e experiências que constituem seus modos de vida, que se encontram alicerçadas na espiritualidade.

Logo, a compreensão da territorialidade, da identidade, da cultura, dos valores e das relações estabelecidas internas e externas situa-se na apreensão dos fenômenos inerentes aos coletivos indígenas, nas quais a espiritualidade parece-nos ser a mais significativa como abordagem teórica e empírica.

\title{
REFERÊNCIAS
}

AGUILERA URQUIZA, A. H. Sustentabilidade e Território - Relação com a Educação Escolar Indígena. In: II Seminário Internacional: Fronteiras ÉtnicoCulturais e Fronteiras da Exclusão - Práticas Educativas num Contexto Intercultural, CD ROM. Campo Grande, 2006. Disponível em http://www.neppi.org/anais/textos/pdf/sustentabilidade territorio relacao educa cao escolar.pdf. Acesso em 01.02.2009.

ALMEIDA SILVA, Adnilson de. Territorialidades e identidade do coletivo Kawahib da Terra Indígena Uru-Eu-Wau-Wau em Rondônia: "Orevaki Are" (reencontro) dos "marcadores territoriais". Tese de Doutorado em Geografia. Curitiba: SCT/DG/PPG/UFPR, 2010. 301 p. 
Impactos socioculturais em populações indígenas de Rondônia: estudo da nação Jupaú. Dissertação de Mestrado em Geografia. Porto Velho: UNIR/PPGG, 2007. 249 p.

SILVA, J. C. Restabelecimento da maloca Yñamõrarikãgã:um espaço de representação cultural do povo Jupaú. In: Anais do II Colóquio Nacional do NEER - Espaços Culturais: Vivência, Imaginações e Representações. Salvador: EDUFBA, 2007. v. II ED. p. 1-17.

ANDRADE, M.C. Geografia, ciência da sociedade: uma introdução à análise do pensamento geográfico. São Paulo: Atlas, 1987.

BONNEMAISON, J. Voyage autour du territoire. L'Espace Geógraphique, $n^{\circ}$ 4. Doin, 8, Place de l'Odéon. Paris: Université Paris VI, 1981. p. 249-262.

CASSIRER, E. Linguagem e mito. 3ª ed. São Paulo: Perspectiva, 1992 [1925].

The Philosophy of symbolic forms. Vol. III. The Phenomenology of Knowledge. New Haven: Yale University Press, 1953-1957 [1929].

Antropología Filosófica: Introdução a uma filosofia de la cultura. $5^{\mathrm{a}} \mathrm{ed}$. México: Fondo de Cultura Económica, 1968 [1944].

Ensaio sobre o homem: introdução a uma filosofia da cultura humana. São Paulo: Martins Fontes, 1994 [1944].

Esencia y efecto del concepto de símbolo. México: Fondo de Cultura Económica, 1975 [1956].

CHEVALIER, J. \& GHEERBRANT, A. Dicionário de Símbolos. Mitos, sonhos, costumes, gestos, formas, figuras, cores, números. $12^{\mathrm{a}}$ ed. Rio de Janeiro: José Olympio, 1998.

GUSDORF, G. Tratado de Metafísica. São Paulo: Ed. Nacional, 1960.

HENRIQUES, I.C. Território e Identidade: o desmantelamento da terra africana e a construção da Angola colonial (c.1872-c1926). Sumário pormenorizado. Lisboa: Faculdade de Letras da Universidade de Lisboa, 2003. p. 1-27.

KOZEL, S. As representações no geográfico. In: MENDONÇA, F. \& KOZEL, $S$. (orgs). Elementos de epistemologia da geografia contemporânea. Curitiba: Ed. UFPR, 2004. p. 215-232.

LANGER, S. Sentimento e forma. São Paulo: Perspectiva, 2006 [1953].

Mind: An essay on human feeling ( 3 vols.). Baltimore: Johns Hopkins University Press. 1967-1985.

Filosofia em nova chave. $2^{\mathrm{a}}$ ed. São Paulo: Perspectiva, 2004 [1942].

LATOUR, B. Políticas da natureza: como fazer ciência na democracia. São Paulo: EDUCS, 2004.

Reassembling the social: An Introduction to Actor-Network-Theory. New York: Oxford University Press, 2005. 
LEENHARDT, M. "J'ai um Corps: le nom et la personnalité". In: LEENHARDT, M. Gens de la Grande Terre. Paris: Gallimard, 1937.

. La Persona a les Societats Primitives. Barcelona: Icaria, 1995.

Barcelona/Buenos Aires: Paidós, 1997 [1947].

LÓPEZ, E. Noções de Corporalidade e Pessoa entre os Jodï. Rio de Janeiro: MANA 12(2), 2006. p. 359-388.

MONTIBELLER Filho, G. O Mito do Desenvolvimento Sustentável: meio ambiente e custos sociais no moderno sistema produtor de mercadorias. $2^{\text {a }}$ Edição Revisada. Florianópolis: Editora da UFSC, 2004.

SACK, R. Human territoriality. Theory and History. Cambridge: Cambridge University Press, 1980.

SAHLINS, M. "O 'pessimismo sentimental' e a experiência etnográfica: porque a cultura não é um 'objeto' em via de extinção (parte I)". Mana Estudos de Antropologia Social, Museu Nacional. Rio de Janeiro, v.3, no 1, UFRJ, 1997. p. 41-73.

. "O 'pessimismo sentimental' e a experiência etnográfica: porque a cultura não é um 'objeto' em via de extinção (parte II)". Mana Estudos de Antropologia Social, Museu Nacional. Rio de Janeiro, v.3, no 2, UFRJ, 1997a. p. 103-150.

. Ilhas de História. Rio de Janeiro: Jorge Zahar, 2003 [1985].

VIVEIROS DE CASTRO, E.B. A fabricação do corpo na sociedade xinguana e alguns aspectos do pensamento Yawalapíti (Alto Xingu): classificações e transformações. In: OLIVEIRA FILHO (Org.). Sociedades indígenas \& indigenismo no Brasil. Rio de Janeiro: Marco Zero, 1987.

Atualização e contra-efetuação do virtual: o processo do parentesco. In: VIVEIROS DE CASTRO, E.B. A inconstância da alma selvagem e outros ensaios de antropologia. $2^{a}$ ed. São Paulo: Cosac \& Naify. 2006, p. 401-456. [2002]. Publicado também em: Ilha. Revista de Antropologia. Vol. 2, № 1, Florianópolis: UFSC, 2002. 